\title{
Screening by coral green fluorescent protein (GFP)-like chromoproteins supports a role in photoprotection of zooxanthellae
}

\author{
E. G. Smith · C. D'Angelo • A. Salih • \\ J. Wiedenmann
}

Received: 27 January 2012/ Accepted: 30 November 2012

(C) Springer-Verlag Berlin Heidelberg 2013

\begin{abstract}
Green fluorescent protein (GFP)-like pigments are responsible for the vivid colouration of many reefbuilding corals and have been proposed to act as photoprotectants. Their role remains controversial because the functional mechanism has not been elucidated. We provide direct evidence to support a photoprotective role of the non-fluorescent chromoproteins (CPs) that form a biochemically and photophysically distinct group of GFP-like proteins. Based on observations of Acropora nobilis from the Great Barrier Reef, we explored the photoprotective role of CPs by analysing five coral species under controlled conditions. In vitro and in hospite analyses of chlorophyll excitation demonstrate that screening by CPs leads to a reduction in chlorophyll excitation corresponding to the spectral properties of the specific CPs present in the coral tissues. Between 562 and $586 \mathrm{~nm}$, the CPs maximal
\end{abstract}

Communicated by Biology Editor Dr. Anastazia Banaszak

Electronic supplementary material The online version of this article (doi:10.1007/s00338-012-0994-9) contains supplementary material, which is available to authorized users.

E. G. Smith · C. D'Angelo

National Oceanography Centre, University of Southampton,

Southampton, UK

E. G. Smith

New York University, Abu Dhabi, Abu Dhabi, UAE

A. Salih

School of Science and Health, University of Western Sydney,

Sydney, Australia

J. Wiedenmann $(\bowtie)$

Ocean and Earth Science, National Oceanography Centre, Southampton/University of Southampton, Southampton, UK e-mail: joerg.wiedenmann@noc.soton.ac.uk absorption range, there was an up to $50 \%$ reduction of chlorophyll excitation. The screening was consistent for established and regenerating tissue and amongst symbiont clades A, C and D. Moreover, among two differently pigmented morphs of Acropora valida grown under identical light conditions and hosting subclade type C3 symbionts, high $\mathrm{CP}$ expression correlated with reduced photodamage under acute light stress.

Keywords Green fluorescent protein (GFP)-like proteins - Chromoproteins - Function · Photoprotection - Growth · Coral-zooxanthellae symbiosis

\section{Introduction}

Corals inhabit a range of light environments spanning two orders of magnitude of irradiance from shallow waters to deeper mesophotic reefs (Lesser et al. 2010). Consequently, corals and their symbionts need mechanisms for acclimation and adaptation to different irradiances, chromaticity and temporal variability in the light field. Even at the scale of a single shallow-water colony, there are large variations in light exposure of the coral's tissues controlled by factors such as seasonal and diel changes in surface irradiance, changes in the absorbing and scattering materials in the water column, orientation of the tissue surface relative to the incident irradiance and wave-focusing effects (Falkowski et al. 1990; Veal et al. 2010; Kaniewska et al. 2011). The shallow-water environments where reefbuilding corals thrive are typified by irradiances often greater than photon fluxes of $\sim 300-750 \mu \mathrm{mol} \mathrm{m}^{-2} \mathrm{~s}^{-1}$ that saturate photosynthesis of the algal symbionts in hospite (Gorbunov et al. 2001; Levy et al. 2004; Hennige et al. 2008). As such, some shallow-water corals live in 
habitats where light is in excess. In addition, other factors, such as temperature stress, may reduce the photosynthetic capacity of the zooxanthellae thus increasing the excess excitation energy (Iglesias-Prieto et al. 1992; Warner et al. 1996; Smith et al. 2005). Exceeding the capacity of the photosynthetic machinery of the algal symbionts can result in photoinhibition and production of reactive oxygen species (ROS) (Smith et al. 2005) that cause damage to cellular components (Lesser 2006). Consequently, both the coral and the symbionts possess mechanisms to reduce light stress. In fact, light stress in combination with elevated water temperatures is considered a fundamental cause of coral bleaching due to increased ROS production and/or inhibition of photosystem II (PSII) repair mechanisms (Tchernov et al. 2004; Smith et al. 2005; Lesser 2006; Takahashi et al. 2009). Furthermore, light is a key driver of nutrient-stress-mediated coral bleaching (Wiedenmann et al. 2012).

Corals' endosymbiotic algae optimise light absorption and usage in response to incident irradiance. The mechanisms employed include long-term acclimation strategies such as changes to the size and/or number of photosynthetic units (PSUs) (Falkowski and Dubinsky 1981; Hennige et al. 2009) as well as acclimatory mechanisms designed to address the supraoptimal irradiances brought about by short-term changes such as diurnal variability. The short-term responses include downregulation of PSII reaction centres (Gorbunov et al. 2001), xanthophyll conversion (Brown et al. 1999), cyclic electron transport and dissociation of antenna complexes from PSII (McCabe Reynolds et al. 2008). The degree to which different acclimatory mechanisms are employed, and their relative contribution to photoprotection, appears to be, at least in part, associated with the genetic identity of the symbiont clade, and hence, there is evidence that some symbiont clades/subclades are better suited to certain environments than others (Iglesias-Prieto et al. 2004; McCabe Reynolds et al. 2008). Nevertheless, in spite of extensive protection afforded by non-photochemical quenching, photodamage to PSII can occur in shallow-water corals on cloud-free days (Gorbunov et al. 2001) and under thermal stress (Warner et al. 1999).

While some host-based responses to light stress are the same as those employed by the symbiont, such as accumulation of MAAs and antioxidant enzymes (Lesser 2006), others remain unique to the host. A photoprotective function has been proposed for the host-based family of green fluorescent protein (GFP)-like pigments that are frequently expressed by anthozoans (Salih et al. 1998, 2000; Wiedenmann et al. 1999; Dove et al. 2001). The host pigments of corals and other anthozoans can be divided into two major groups: the fluorescent proteins (FPs), responsible for cyan to red hues and the non-fluorescent chromoproteins (CPs; synonym: pocilloporins), that produce the intense pink, purple and blue pigmentation (Dove et al. 2001; Salih et al. 2006; Alieva et al. 2008; D'Angelo et al. 2008). The CPs and FPs are thought to protect the symbionts from high irradiances by absorbing photons or distributing them away from the algal pigments by reemission or reflectance (Salih et al. 1998, 2000, 2006; Wiedenmann et al. 1999; Dove et al. 2001). It is proposed that these pigments act through screening (Salih et al. 2000), a process whereby the light received by the photosynthetic pigments has passed through a layer or compartment containing the photoprotective pigments (Merzlyak et al. 2008). As such, screening is distinct from other photoprotective systems where the photoprotectants and the photosynthetic pigments directly compete for light absorption (Merzlyak et al. 2008).

The high abundance of fluorescent colour morphs in shallow water, the resistance of their zooxanthellae against photoinhibition, the stability and slow turnover of the GFPlike pigments and their light-regulated expression support a photoprotective function (Wiedenmann et al. 1999; Salih et al. 2000; Leutenegger et al. 2007a; D'Angelo et al. 2008). Nevertheless, the functional mechanism of photoprotection by GFP-like proteins is controversial as no reduction due to GFP absorption was evident in the chlorophyll excitation spectrum of zooxanthellae in Caribbean corals (Mazel et al. 2003). Also, high-level expression of GFP-like proteins in zooxanthellae-free coral growth zones and in several azooxanthellate anthozoans from low-light habitats, including the deep sea, sheds doubts on whether all of these pigments fulfil a photoprotective function (Wiedenmann et al. 2004a; D'Angelo et al. 2008; Vogt et al. 2008; D'Angelo et al. 2012). In addition to questions about the photoprotective role of FPs, the direct effects of CPs on symbiont photosynthesis remain unclear because the $\mathrm{CP}$ absorption peaks are outside the photosynthetic pigments' major absorption bands (D'Angelo et al. 2008; Dove et al. 2008). These observations together with the results of molecular phylogenetic analyses of the protein sequences suggest that distinct groups of GFP-like proteins could fulfil various functions among different taxonomic groups (Alieva et al. 2008; D'Angelo et al. 2008, 2012).

We observed blue morphs of Acropora nobilis with notably higher zooxanthellae and photosynthetic pigment concentrations than their brown counterparts growing adjacently in a shallow-water reef setting at Heron Island (Electronic Supplemental Material (ESM) Methods, Fig. S1). The increased density and pigment content of the zooxanthellae could be interpreted as a shade acclimation due to screening by the blue chromoprotein, which is the dominant host pigment in these individuals. This observation was the motivation for our study of the role of CPs in coral photobiology. Considering CPs as a key group of 
GFP-like proteins that are biochemically and photophysically distinct from their fluorescent counterparts (Alieva et al. 2008; Nienhaus and Wiedenmann 2009), we set out to address three questions: Do CPs screen certain wavelengths of visible light that would otherwise be absorbed by the zooxanthellae photosynthetic pigments? Are the symbionts screened by CPs less susceptible to high irradiances in the relevant spectral range? Is screening relevant to growth zones where symbiont densities are low?

\section{Methods}

Coral collection and culture

\section{Collection}

Field samples (branch fragments $\sim 10 \mathrm{~cm}$ length) of brown and blue morphs of Acropora nobilis, growing adjacently, were collected at $\sim 1.5 \mathrm{~m}$ depth at low tide on the outer reef slope of Heron Island, Great Barrier Reef (Marine Parks Permit No. G26894.1) selecting the most lightexposed branches for analysis.

\section{Culture}

Five coral species from the Coral Reef Laboratory mesocosm at the National Oceanography Centre Southampton (D'Angelo and Wiedenmann 2012) were selected based on their CP expression: Acropora valida, Acropora polystoma, Acropora millepora, Seriatopora hystrix and Montipora foliosa. CP-pigmented morphs of A. valida, A. millepora and $S$. hystrix were analysed for comparison of the optical properties of light-exposed and shaded tissue. A. valida colonies were also used to compare photophysiological responses to light stress between the brown and purple morphs. M. foliosa and A. polystoma were incorporated into the study to explore the effects of localised $\mathrm{CP}$ expression in growth zones.

Seriatopora hystrix (D'Angelo et al. 2008) and A. polystoma (D'Angelo et al. 2012; Wiedenmann et al. 2012) of unconfirmed geographical origin were purchased from the ornamental trade. The other species were collected from Fijian reefs and acquired through the Tropical Marine Centre (London, UK) (D’Angelo et al. 2012). Corals were acclimated to tank conditions for at least 18 months prior to the experiments. Briefly, corals were grown under a 12 -h light:dark cycle provided by $250-\mathrm{W}$ metal halide lamps (ESM Fig. S2; Aqualine 10000 $(13,000 \mathrm{~K})$, Aqua Medic, Germany), with the temperature kept at $24{ }^{\circ} \mathrm{C}\left( \pm 0.5^{\circ} \mathrm{C}\right)$ during the experiments.

Fragments of A. valida, A. millepora and S. hystrix were grown perpendicular to the incident irradiance for
$>1$ month to enable acclimation to the light field and induce a localised expression of CPs in the light-exposed parts of the colonies. Measurements with a Li-Cor LI-250A indicated that the upper sides of the coral branches were exposed to photon fluxes of $\sim 200 \mu \mathrm{mol} \mathrm{m}{ }^{-2} \mathrm{~s}^{-1}$. The underside of the branches received $\sim 10 \mu \mathrm{mol} \mathrm{m}^{-2} \mathrm{~s}^{-1}$ of reflected photons.

Characterisation of zooxanthellae

Zooxanthellae densities and pigment content were determined using standard protocols (Parsons and Strickland 1963; Marsh 1970; Jeffrey and Humphrey 1975; Leutenegger et al. 2007b). The dominant zooxanthellae clade in the purple and brown morphs of A. valida was determined by restriction fragment length polymorphism (RFLP) analyses of the amplified small-subunit ribosomal-DNA (SSU rDNA) (Hartle-Mougiou et al. 2012). Analyses of the PCR amplified internal-transcribed spacer region 2 (ITS2) (LaJeunesse 2002) identified the dominant symbiont subclade (Clade C3; Genbank accession numbers from KC405646 to KC405651) of A. valida colour morphs used in the light stress assay.

\section{Reflectance}

Coral reflectance spectra, of S. hystrix, M. foliosa and A. polystoma, were recorded (Mazel et al. 2003) using a fibre-optic reflectance probe connected to an Ocean Optics USB4000 spectrometer and a tungsten halogen HL-2000HP light source (Ocean Optics, USA) with a Spectralon $99 \%$ diffuse reflectance standard as a reference (Labsphere, USA). Five independent reflectance $(R)$ measurements were taken from different locations on each colony and used to estimate absorbance $\left(D_{\mathrm{e}}\right)$ using the formula $D_{\mathrm{e}}=\log (1 / R)$ (Enriquez et al. 2005).

\section{Fluorescence spectroscopy}

Chlorophyll excitation spectra were measured as fluorescence excitation of PSII (680 nm) emission using a Varian Cary Eclipse fluorescence spectrophotometer with a fibreoptic attachment (Leutenegger et al. 2007a; D'Angelo et al. 2008). Chlorophyll excitation spectra were recorded and analysed as per ESM methods.

$\mathrm{CP}$ purification and quantification

CPs were enriched by isopropanol precipitation (Wiedenmann et al. 2000) and further purified by size-exclusion chromatography, where required (Wiedenmann et al. 2002). The CP spectra were measured on a Cary absorption spectrophotometer (Varian, USA). Three CPs were cloned 
from A. millepora (Genbank accession: KC349891, KC411499, KC411500) (D'Angelo et al. 2008). Together with asCP562 from Anemonia sulcata (Genbank Accession: AF322222) (Wiedenmann et al. 2000), the pigments were recombinantely expressed and purified (Wiedenmann et al. 2002). CP concentrations were quantified as described in ESM methods.

\section{In vitro $\mathrm{CP}$ screening}

An in vitro experiment was performed to assess the potential for CPs to screen zooxanthellae in the absence of confounding variables.

Symbionts were isolated from A. sulcata (clade A) (Visram et al. 2006) and two A. valida colonies (clade C and D), washed and resuspended in sterile filtered seawater. Freshly isolated zooxanthellae were loaded into an 8-well culture chamber and allowed to settle for $15 \mathrm{~min}$. Twomillimetre-deep chambers containing CPs and a phosphatebuffered saline (PBS) control were placed between the settled symbionts and the fluorescence spectrometer's fibre-optic probe and chlorophyll excitation spectra were recorded. The CP/PBS filter was used on the same population of the respective clade to ensure comparisons of identical populations with the same physiology and photobiology. The zooxanthellae concentrations $\left(1.0 \times 10^{6}\right.$ cells per $\mathrm{cm}^{-2}$ of the bottom of the wells) used in this experiment are comparable to the symbiont density of the blue morphs of Acropora nobilis at $\sim 1.5 \mathrm{~m}$ at Heron Island (ESM Fig. S1). The CPs selected for analysis were asulCP562 (Wiedenmann et al. 2000), amilCP580 and amilCP604 to enable demonstration of the impact of CPs over their range of absorption peaks. The concentrations of each CP filter were calculated to provide the same peak absorbance as the areal tissue concentrations of CP found in a purple morph of A. valida $\left(0.09 \mathrm{mg} \mathrm{cm}^{-2}\right)$.

\section{Light stress experiment}

Brown and purple morphs of A. valida, both hosting subclade C3 symbionts and grown under a photonflux of $200 \mu \mathrm{mol} \mathrm{m}{ }^{-2} \mathrm{~s}^{-1}$ on the light-exposed sides, were subjected to an additional $1,000 \mu \mathrm{mol} \mathrm{m} \mathrm{m}^{-2} \mathrm{~s}^{-1}$ of orange light (peak spectral irradiance $=595 \mathrm{~nm}$; ESM Fig. S2) provided by an LED array (P4 Amber Star, Seoul Semiconductor, Korea) for 2 days with a 12:12 h light: dark cycle. Chlorophyll fluorescence parameters were recorded using a Diving PAM including exposure to dim light $\left(<5 \mu \mathrm{mol} \mathrm{m} \mathrm{m}^{-2} \mathrm{~s}^{-1}\right)$ prior to and during measurements taken after $12 \mathrm{~h}$ dark acclimation to minimise the impacts of chlororespiration (Warner et al. 2010). The PSII maximum quantum efficiency $(\mathrm{Fv} / \mathrm{Fm})$ was recorded prior to the experiment and at the end of the second dark cycle. The effective quantum yield ( $\Delta \mathrm{F}^{\prime} / \mathrm{Fm}$ ') was measured at the end of the second light cycle. Due to the slow relaxation time of chronic photoinhibition (Gorbunov et al. 2001), any reduction in $\mathrm{Fv} / \mathrm{Fm}$ from the start of the experiment to the end of each dark cycle should indicate PSII damage.

$\mathrm{CP}$ expression in growth zones

A. polystoma and M. foliosa were used to assess the effects of CPs in growth zones as CP expression is localised to these regions in these species. Approximately $1 \mathrm{~cm}^{2}$ of tissue was removed from replicate colonies of A. polystoma to assess $\mathrm{CP}$ expression in regenerating tissue. Half of the colonies were moved to low-light conditions $(\sim 60 \mu \mathrm{mol}$ $\mathrm{m}^{-2} \mathrm{~s}^{-1}$ ), whereas others were left under higher light intensities $\left(\sim 200 \mu \mathrm{mol} \mathrm{m}{ }^{-2} \mathrm{~s}^{-1}\right)$. After 10 days, spectroscopic characterisations of the regenerating areas were made and tissue samples were analysed for protein and zooxanthellae content.

Replicate colonies of two colour morphs of M. foliosa were grown under $\sim 150 \mu \mathrm{mol} \mathrm{m} \mathrm{m}^{-2} \mathrm{~s}^{-1}$. The purple morph expresses the $\mathrm{CP}$, mfolCP577, exclusively in the growth margins of the colony, whereas $\mathrm{CP}$ expression is essentially absent from the brown morph (D'Angelo et al. 2012). Spectroscopic measurements were taken on both the growth margins and centres of the colonies.

\section{Results}

\section{CP spectral properties}

The CPs isolated from the studied coral species had absorption peaks ranging from 562 to $586 \mathrm{~nm}$ (ESM Fig. S3). The pink appearance of $S$. hystrix is due to the accumulation of shysCP562 with an absorption maximum at $562 \mathrm{~nm}$ (D'Angelo et al. 2008), the shortest wavelength of this set of CP pigments. The M. foliosa and A. valida colonies contain CPs with peak absorptions at 577 and $580 \mathrm{~nm}$, respectively, (herein referred to as mfolCP577 (D'Angelo et al. 2012) and avalCP580). Consequently, the pigmented regions of the corals appear purple-violet. We cloned three CPs from A. millepora (amilCP580, ami1CP586 and amilCP604) with absorption maxima at 580, 586 and $604 \mathrm{~nm}$. The absorption spectrum of partially purified tissue extracts from a blue A. millepora morph peaked at $586 \mathrm{~nm}$ suggesting that the blue colour of the coral results from a dominant expression of amilCP586. The molar extinction coefficients were approximated for two proteins, avalCP580 $\left(183,000 \mathrm{M}^{-1} \mathrm{~cm}^{-1}\right)$ and apolCP584 (103,000 $\left.\mathrm{M}^{-1} \mathrm{~cm}^{-1}\right)$. Absorption spectra and molar extinction coefficients are typical of anthozoan CPs (Alieva et al. 2008). 
In vitro $\mathrm{CP}$ screening

The three Symbiodinium clades showed similar chlorophyll excitation spectra with major peaks at around 460 and $525 \mathrm{~nm}$ (Fig. 1). While the excitation spectra for clades $\mathrm{C}$ and $\mathrm{D}$ were almost identical, the contribution of the $525 \mathrm{~nm}$ peak in the clade A spectra was reduced, with a maximum difference between them at $\sim 520 \mathrm{~nm}$. The latter was likely due to differences in the zooxanthellae pigment composition as this peak has been attributed to peridinin (McCabe Reynolds et al. 2008). When a CP solution was placed between the zooxanthellae and the fibre-optic probe, mimicking the localisation and concentration of CPs in pigmented coral tissue, there was a clear decrease in chlorophyll excitation by up to $18 \%$ compared to the 400-620 nm spectrum. The wavelength-specific reduction was up to $55 \%$ at $580 \mathrm{~nm}$ for amilCP580. This decrease in chlorophyll excitation was consistent with the CP absorption characteristics, with excellent agreement between the difference spectra and the $\mathrm{CP}$ absorption spectra for all three clades.

Impact of CPs on the optical properties of S. hystrix

To confirm the applicability of our in vitro experiment, we performed measurements on a pink colony of $S$. hystrix that expressed a CP absorbing at $562 \mathrm{~nm}$ (Fig. 2). In agreement with the in vitro study, the presence of a $\mathrm{CP}$ in light- exposed tissue resulted in decreased chlorophyll excitation corresponding to the $\mathrm{CP}$ absorption properties.

The reflectance spectra of the upper and lower sides of the $S$. hystrix colony fall into the two categories described by Hochberg et al. (2004) for corals in the field. The shaded undersides yielded reflectance spectra showing maxima at around 575, 600 and $650 \mathrm{~nm}$ typical of "brown" corals (Hochberg et al. 2004). In contrast, the reflectance spectrum of light-exposed pigmented tissue showed features characteristic of "blue" corals: the $575 \mathrm{~nm}$ maximum was absent, resulting in a plateau-like shape between 600 and $650 \mathrm{~nm}$ (Hochberg et al. 2004). Converting these data into estimated absorbance highlights a maximum at $\sim 555 \mathrm{~nm}$ for the light exposed side. Comparisons of the difference between the absorbance of the upper and lower tissues with the absorption spectrum of shysCP562 reveal a strong similarity between the feature at $\sim 566 \mathrm{~nm}$ in the difference spectrum and the $\mathrm{CP}$ absorbing at $562 \mathrm{~nm}$.

\section{Relationship between excitation difference and CP absorption}

To further investigate CP-mediated screening of symbionts in hospite, we compared the excitation difference spectra of light-exposed versus shaded sides, against the absorption properties of the respective CP in S. hystrix, A. valida and A. millepora (Fig. 3). Not only did the shapes of the difference spectra match the $\mathrm{CP}$ absorption spectra but the

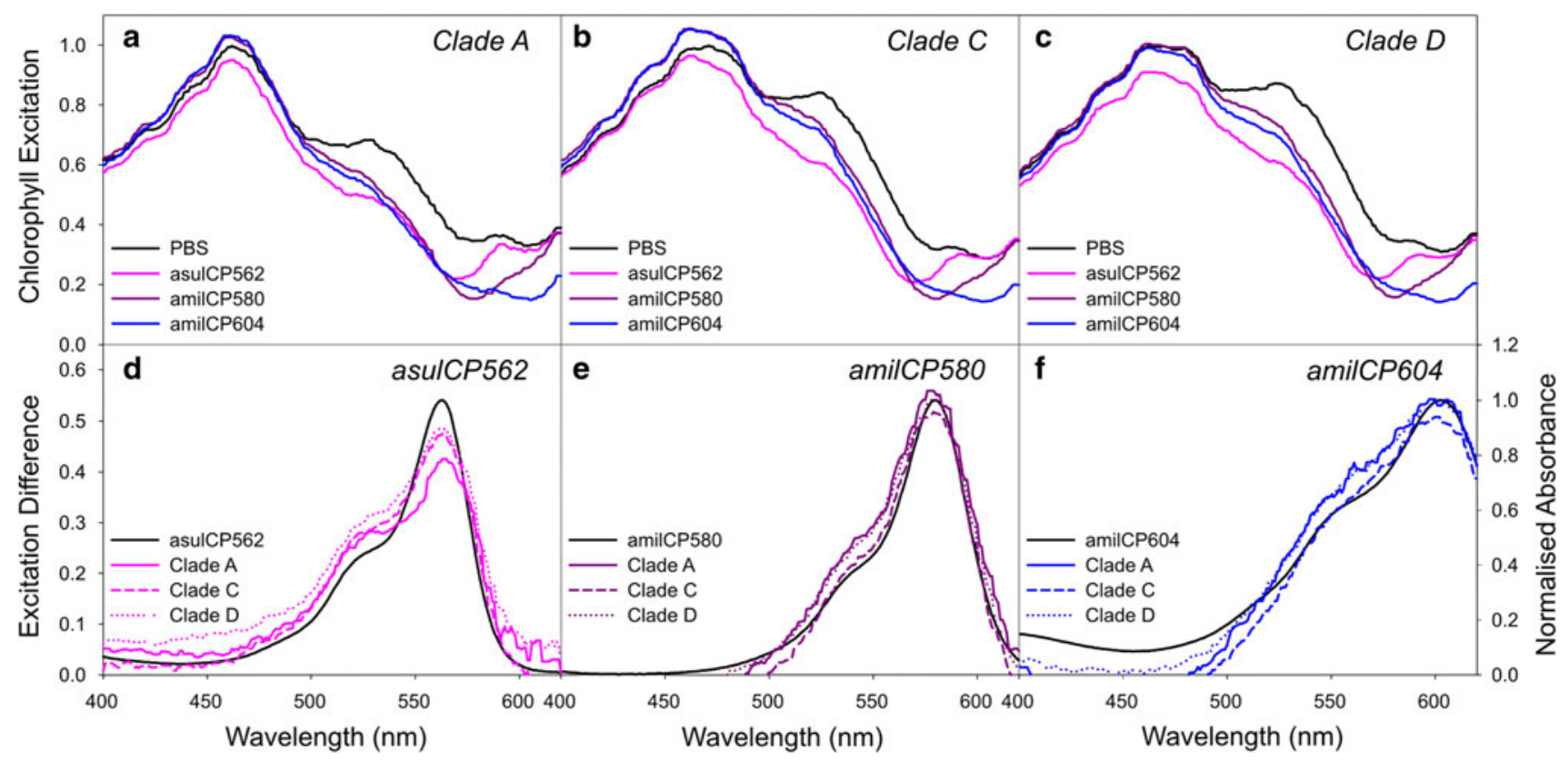

Fig. 1 In vitro assessment of chromoprotein screening. Chlorophyll excitation spectra of freshly isolated zooxanthellae of clades A (a), C (b) and D (c) through solutions of PBS, asulCP562, amilFP580 and amilCP604. Fluorescence spectra are normalised to the PBS excitation spectrum peak. Excitation difference spectra through the
asulCP562 (d), amilCP580 (e) and amilCP604 (f) solutions from clade A, C and D zooxanthellae. The absorption spectra of the respective CPs are shown for reference and are normalised to a peak value of 1 


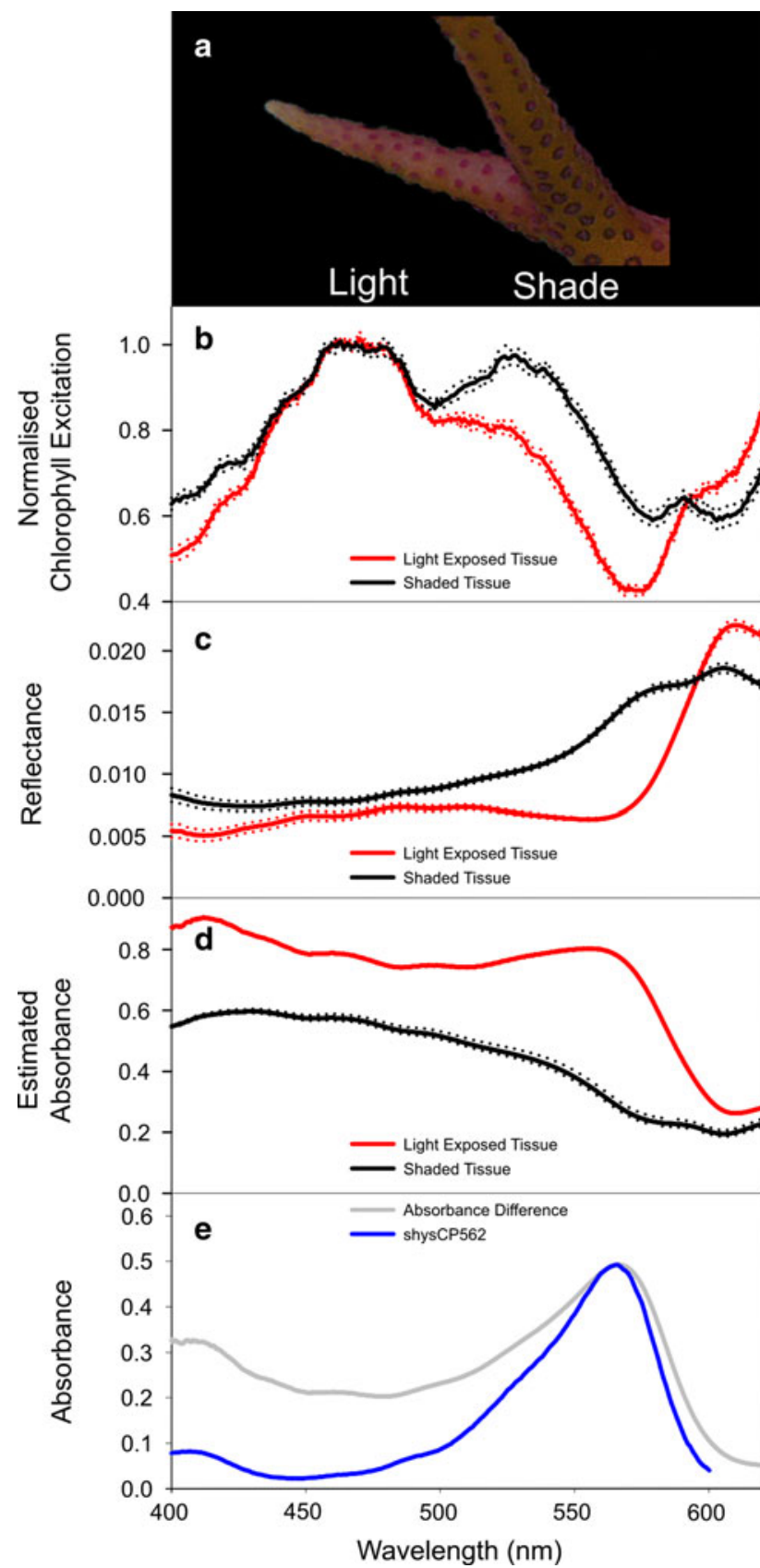

Fig. 2 Impact of shysCP562 on the optical properties of S. hystrix. a Photograph showing the accumulation of shysCP562 in the lightexposed tissues of $S$. hystrix. b-d Normalised chlorophyll excitation (b), reflectance (c) and estimated absorbance (d) spectra of the lightexposed and shaded surfaces. Solid lines are the mean of five measurements, with the $\pm \mathrm{SD}$ indicated by dotted lines. e The difference between absorbance of light-exposed and shaded tissues. The absorption spectrum of shysCP562 is shown for reference

peak locations showed good agreement across the $24 \mathrm{~nm}$ range of the CPs' absorption maxima (562-586 nm). By compiling the data from five species and different types of comparisons (light vs shaded tissues, growth vs non-growth zones and CP-pigmented vs non-pigmented morphs), we
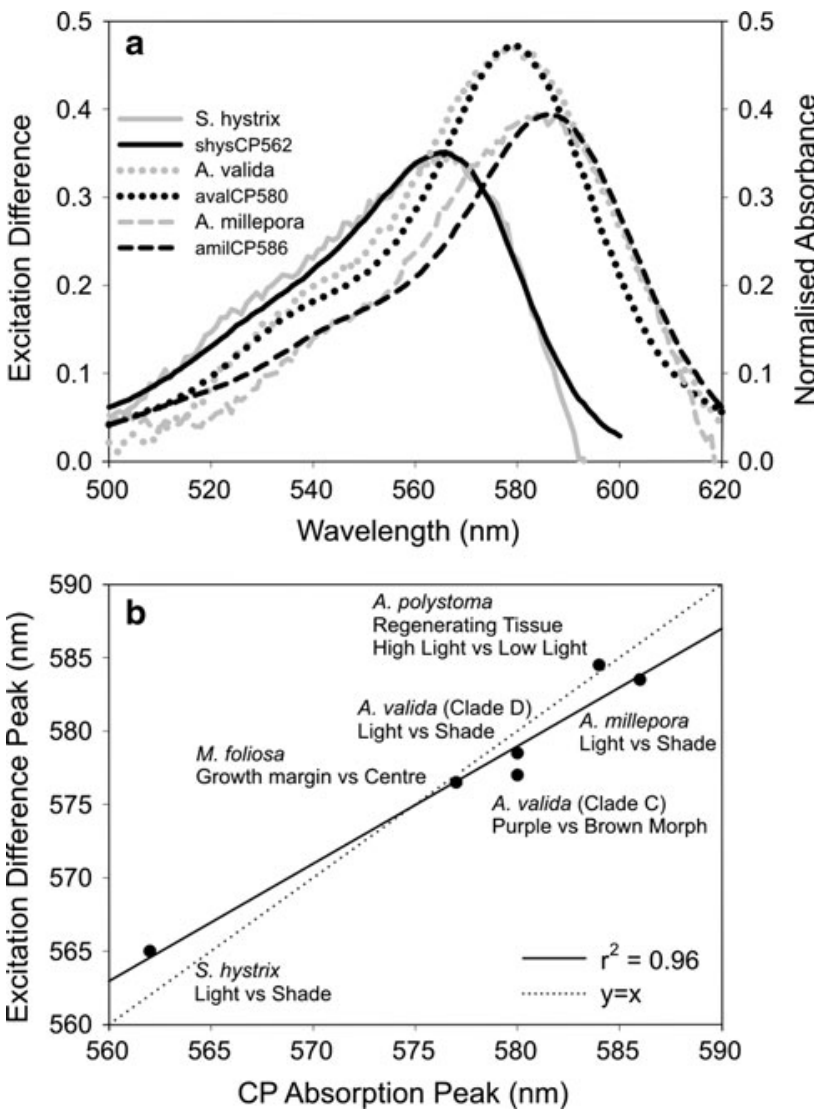

Fig. 3 The relationship between the excitation difference spectra and the respective $\mathrm{CP}$ absorption. a Comparison between the excitation difference spectra of $S$. hystrix, A. valida and A. millepora, and the respective CPs (shysCP562, avalCP580, amilCP586) absorption spectra. b Linear relationship between the CP absorption peak and the peak of the excitation difference spectrum. Each point represents the comparison between pigmented and non-pigmented tissue from five coral species (S. hystrix, A. valida, A. millepora, A. polystoma and M. foliosa). A. valida is represented twice from comparisons between light and shaded tissue of a purple morph hosting clade D symbionts and between the brown and purple morphs hosting clade $\mathrm{C}$ symbionts

identified a strong linear relationship $\left(r^{2}=0.96\right)$ between the peak of excitation difference spectra and the CP absorption maxima.

Response of colour morphs to high irradiances

Using the purple and brown morphs of $A$. valida, we compared the response of CP-pigmented and non-CP-pigmented tissues to high irradiances to explore the impacts of CP screening on the light stress response of zooxanthellae (Fig. 4). Both colour morphs host subclade C3 zoxanthellae as the dominant symbiont strain. Prior to experimentation, the corals were grown side-by-side at an orthogonal angle to the incident light $\left(200 \mu \mathrm{mol} \mathrm{m}{ }^{-2} \mathrm{~s}^{-1}\right)$ to ensure that they experienced comparable light histories. As CPs 
are upregulated in response to light, they are essentially absent in corals exposed to low light, but their tissue content increases in proportion to photon flux densities beyond $100 \mu \mathrm{mol} \mathrm{m} \mathrm{m}^{-2} \mathrm{~s}^{-1}$ (D'Angelo et al. 2008). As a consequence, the ectodermal tissue of the branch upperside of the purple morph (ESM Fig. S4) shows a strongly increased expression of avalCP580 compared to the brown morph (Fig. 4). The branch undersides of both morphs are essentially CP free. Differences in the response to high irradiance were observed when the uppersides of the branches of the morphs were exposed to intense orange light $\left(1,000 \mu \mathrm{mol} \mathrm{m} \mathrm{m}^{-2} \mathrm{~s}^{-1}\right)$. Over the course of the light stress experiment, zooxanthellae of both morphs showed a clear reduction in the maximum quantum yield ( $\mathrm{Fv} / \mathrm{Fm})$ after dark recovery. However, the decline in the upper branch sides was significantly greater in the brown morph with an almost $50 \%$ reduction compared to $21 \%$ in the purple morph (Mann-Whitney $U$ test, $p<0.05$ ). Similarly, the purple morph also showed a higher effective quantum yield at the end of the second light cycle than the brown morph. Only the branch upperside of the brown morph appeared visibly bleached by the end of the treatment (Fig. 4). When the shade-acclimated sides of the colonies, both without $\mathrm{CP}$ pigmentation, were exposed to the same conditions, the decline in the maximum quantum yield $(>75 \%)$ was considerably larger than for the light-acclimated uppersides of the branches. The decrease was comparable between morphs (Mann-Whitney $U$ test, $p=0.421$ ) and consistently observed for the effective quantum yield. In both morphs, the treatment resulted in a bleached appearance of the shade-acclimated branch sides (Fig. 4).

\section{Growth zone CP expression}

Regenerating tissue of A. polystoma grown under higher light contained very low symbiont densities, whereas the new tissue of the low-light sample was fully colonised by zooxanthellae (Fig. 5). Under the higher light conditions, the tissue content of apolCP584 contributed $\sim 6 \%$ to the total soluble protein of the high-light regenerating tissue, representing an $\sim 30$-fold greater $\mathrm{CP}$ content than the new tissue grown under low light. The difference in CP concentration is reflected in the chlorophyll excitation spectra, with the higher $\mathrm{CP}$ content in the high-light tissue resulting in a relative reduction in chlorophyll excitation peaking at $582 \mathrm{~nm}$. CP absorption was evident in the spectra of the high-light regenerating tissue. In agreement with our findings for M. foliosa (ESM Fig. S5), the lack of absorption by algal pigments in regenerating tissue under high light results in a high reflectance in the blue-green spectral range (ESM Fig. S6).
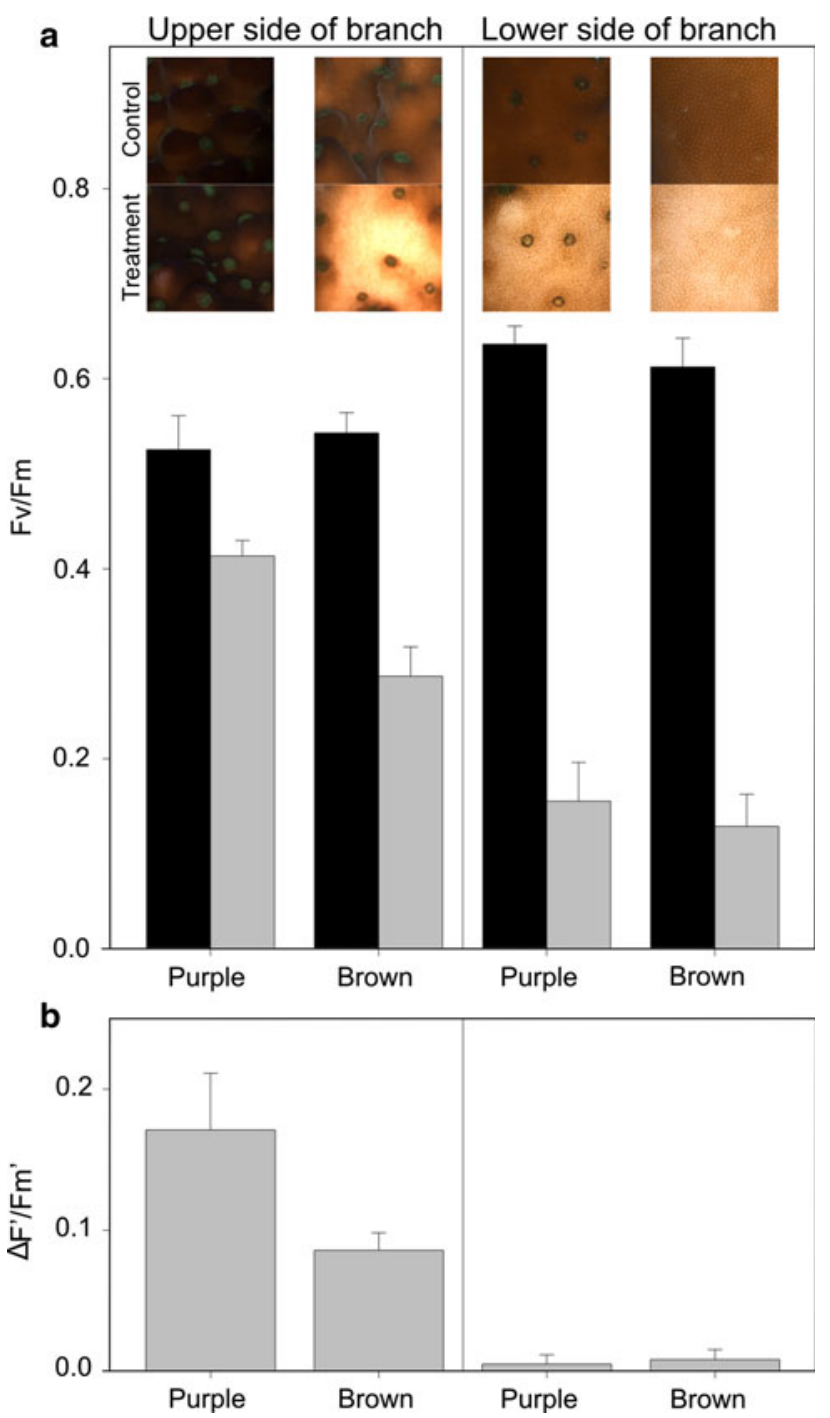

Fig. 4 The impacts of light stress on the photobiology of brown and purple $A$. valida morphs hosting subclade C3 symbionts. Comparison of maximum quantum yields before (black bars) and after (grey bars) the light stress treatment for light-acclimated upper (left panel) and shade-acclimated lower (right panel) tissues. The effective quantum yields are shown by the light grey bars and were performed prior to the end of the light stress treatment. The error bars show the \pm SD of 5 measurements. Inset: Photographs showing control and treatment corals

\section{Discussion}

The family of GFP-like proteins represents an important group of host pigments in reef-building corals and other anthozoans (Matz et al. 1999; Wiedenmann et al. 1999, 2000, 2004a; Salih et al. 2000; Dove et al. 2001; Alieva et al. 2008). It was proposed that these pigments exert a photoprotective function in corals and sea anemones by absorbing photons or redistributing them away from the major absorption bands of the photosynthetic pigments of the algal symbionts (Wiedenmann et al. 1999; Salih et al. 

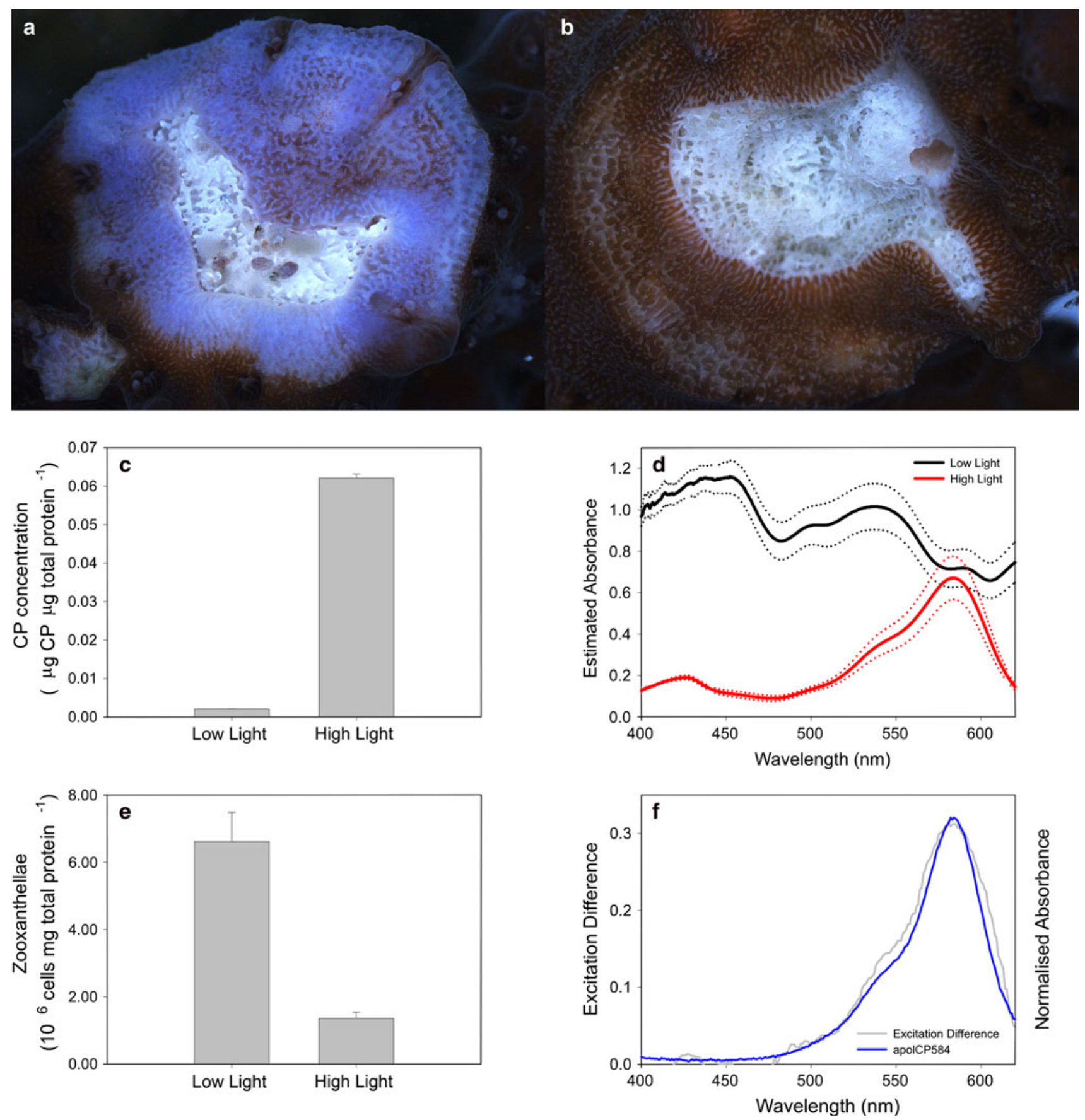

Fig. 5 Regulation of $\mathrm{CP}$ expression in regenerating tissue of A. polystoma under different light conditions. a, b Photographs of A. polystoma regeneration zones grown under high $(\mathbf{a} ; \sim 200 \mu \mathrm{mol}$ $\mathrm{m}^{-2} \mathrm{~s}^{-1}$ ) and low $\left(\mathbf{b} ; \sim 60 \mu \mathrm{mol} \mathrm{m} \mathrm{m}^{-2} \mathrm{~s}^{-1}\right.$ ) light. c, e CP (c) and zooxanthellae (e) content of regenerating tissue under the two light conditions. Error bars indicate the $\pm \mathrm{SD}$ of triplicate measurements.

d Mean estimated absorbance for the low- and high-light tissue. Dotted lines show the $\pm \mathrm{SD}$ of 5 independent measurements. $f$ The excitation difference spectra of high- versus low-light regenerating tissue. The absorption spectrum of apolCP584 is shown for reference and is normalised to the height of the difference spectrum

2000; Dove et al. 2001). However, a general function of GFP-like proteins as photoprotectants has been controversial (Mazel et al. 2003; D'Angelo et al. 2008) and observations suggest functional heterogeneity among members of this large protein family (Alieva et al. 2008; D'Angelo

et al. 2008; Vogt et al. 2008). We tested the large group of non-fluorescent CPs for their potential to screen light that would be destined for zooxanthellae absorption, whether this screening provides relief from light stress and if screening is applicable to regions of low symbiont density. 


\section{$\mathrm{CP}$ screening}

A previous study of 19 Caribbean coral species concluded that GFPs were not photoprotective as FPs did not significantly alter the chlorophyll excitation spectrum nor did they increase coral reflectance (Mazel et al. 2003). In contrast, we found that CPs have a pronounced effect on the algal chlorophyll excitation spectrum, with a clear decrease around the $\mathrm{CP}$ absorption maxima, both in vitro and in hospite.

The in vitro analyses provide a unique standpoint from which to monitor the $\mathrm{CP}$ effects on the chlorophyll excitation spectrum. Measurements were taken on identical populations of each clade of isolated zooxanthellae with different CP filters, and therefore, differences between the excitation spectra could be attributed solely to the CPs rather than differences in algal photobiology. While an in vitro experimental setup may not accurately represent the complex light environment of a coral's tissues (Kuhl et al. 1995; Enriquez et al. 2005), the close agreement in the degree of chlorophyll excitation reduction $(\sim 50 \%$ at $580 \mathrm{~nm}$ ) between our in vitro experiments (clade D, amilCP580) and an A. valida (clade D, avalCP580) colony from which the $\mathrm{CP}$ concentrations were calculated demonstrates that the results are indeed relevant to the in hospite $\mathrm{CP}$ function. Furthermore, the results show that screening occurs across the $\mathrm{CP}$ maximal range (562-604 nm). The measurable impact of CPs can be attributed to their high molar extinction coefficients, which tend to be significantly greater than those of their fluorescent counterparts, especially GFPs (Salih et al. 2006; Alieva et al. 2008; Nienhaus and Wiedenmann 2009).

The spectral analyses of zooxanthellae in hospite support the findings of the in vitro experiment, while furthering our knowledge of how CPs alter corals' optical properties. The excellent agreement between the excitation difference and $\mathrm{CP}$ absorption spectra clearly demonstrates the CP-mediated screening effect.

It is important to stress that screening in coral tissue is due to the physical separation of the two absorbing species, the zooxanthellae and the CPs. The light received by the gastrodermal zooxanthellae is directly dependent on the absorption and scattering occurring in the ectoderm that separates them from the external light field. The ectodermal CPs absorb light of certain wavelengths thereby reducing the amount of photons reaching the zooxanthellae in the endoderm. This screening results in a reduction in the chlorophyll excitation similar to the screening by epidermal anthocyanins in higher plants (Liakopoulos et al. 2006; Merzlyak et al. 2008).

CPs absorb photons in a spectral range that lies mostly outside the major absorption bands of photosynthetic pigments (D'Angelo et al. 2008; Dove et al. 2008).
Therefore, it has been argued that any photoprotection afforded by CPs is likely to be indirect, for instance, by a blue-light enrichment of the internal light field that promotes chlorophyll retention, increased antioxidant pools and expression of photoprotective Early Lightinducible Proteins (ELiPs) (Dove et al. 2008). While these assertions are likely valid, our results demonstrate that the role of $\mathrm{CP}$ absorption in photoprotection is also direct, particularly as the in vitro experiment demonstrated that total chlorophyll excitation between 400 and $620 \mathrm{~nm}$ could be reduced by up to $18 \%$. The zooxanthellae chlorophyll excitation spectra determined for five coral species clearly show that light-use efficiency is less spectrally discriminant than absorption spectra of the pigments in dilute solutions would suggest. These results are consistent with photosynthetic action-spectra measured with fluorescence (Lesser et al. 2000; Mazel et al. 2003) and oxygen sensors (Kuhl et al. 1995) where the intensity parameter is the incident irradiance. This effect results from strong scattering and pigment-packaging occurring at the level of the symbionts inside the coral tissue (Kirk 1994; Stambler and Dubinsky 2005). As a result, the contribution of wavelengths outside the major pigment absorption bands to the excitation of the symbionts' chlorophyll fluorescence is substantial.

Photosynthetic antennae may not be the only site responsible for photodamage as the manganese complex of the oxygen evolving complex (OEC) has also been implicated in photoinhibition (Hakala et al. 2005; Baird et al. 2009; Takahashi et al. 2010). Although predominantly absorbing in the UV region of the spectrum, high photon fluxes throughout the visible spectrum can cause damage to the OEC (Hakala et al. 2005). Indeed, Takahashi et al. (2010) found that the yellow-orange region of the visible spectrum is the most damaging for higher plants despite low absorption in this spectral range by photosynthetic pigments. In fact, yellow-orange light remains an important spectral component in shallow water (Kirk 1994). Dustan (1982) found that even at $3 \mathrm{~m}$ depth, a Caribbean reef received more light at $567 \mathrm{~nm}$ than in blue wavelenths $<500 \mathrm{~nm}$. As other existing holobiont photoprotective mechanisms, such as MAA accumulation, act outside the yellow-orange range, the CPs in shallow-water corals might provide protection in a vulnerable spectral window, functioning in a similar manner as anthocyanins in higher plants (Merzlyak et al. 2008). Finally, important physiological processes in corals, including regulation of genes encoding GFP-like proteins, are controlled by blue light (Levy 2003; Levy et al. 2006; D’Angelo et al. 2008; Kaniewska et al. 2009). Hence, the removal of photons in the longer wavelength range appears to be a sensible strategy to avoid interference between photoprotection and blue-light-regulated processes. 
$\mathrm{CP}$ screening correlates with reduced photodamage

We assessed the potential of screening to afford relief from light stress by subjecting two colour morphs of A. valida to high photon fluxes of yellow-orange light $\left(1,000 \mu \mathrm{mol} \mathrm{m} \mathrm{m}^{-2} \mathrm{~s}^{-1}\right)$ and measuring the reduction in the maximum quantum yield in response to light stress after $12 \mathrm{~h}$ dark recovery. This value is indicative of photodamage rather than dynamic photoinhibtion as the dynamic processes should relax within $\sim 3 \mathrm{~h}$ (Gorbunov et al. 2001). The method has been used in previous studies and the results correlate with changes in other photodamage biomarkers such as D1 concentration and symbiont cell viability (Warner et al. 1999; Gorbunov et al. 2001; Franklin et al. 2004). We found that the CP-containing tissues of the branch uppersides of the purple morph of A. valida suffered less photodamage under high-light stress compared to the brown morph. In contrast, comparable damage was observed when the CP-free tissue of the branch undersides of both morphs was subjected to the light stress treatment. Hence, the finding that zooxanthellae in tissues containing high $\mathrm{CP}$ concentrations show reduced damage under the impact of light stress strongly supports an ecologically relevant photoprotective function of CPs. It is important to stress, however, that CP expression is certainly not vital for shallow-water corals, otherwise it would be ubiquitous. Instead, they are likely to represent a strategy for extending the ecological niche of certain species. It is established that zooxanthellae have mechanisms that are effective in protecting the photosynthetic apparatus under supraoptimal irradiances (Gorbunov et al. 2001), and therefore, it has been questioned whether there is a need for additional host-based photoprotectants (Mazel et al. 2003). However, there is evidence that under shallow-water light conditions on a cloud-free day and under thermal stress, the symbionts' capacity for photoprotection can be exceeded and photodamage can occur (Iglesias-Prieto et al. 1992; Warner et al. 1999; Gorbunov et al. 2001). We propose that under these conditions, $\mathrm{CP}$ expression may help the coral to minimise light stress. Moreover, the CPs could additionally act to promote survival during occasional periods of extraordinary stress.

A photoprotective role for GFPs has been questioned because bathymetric studies of the GFP content of Montastraea faveolata and $M$. cavernosa showed no significant correlation with depth and other species lacked the lightdependent regulation of GFP-like proteins that would be expected for a typical photoprotectant (Mazel et al. 2003; Wiedenmann et al. 2004b; Leutenegger et al. 2007a; Vogt et al. 2008). However, D'Angelo et al. (2008) demonstrated a light intensity-controlled production of FPs and CPs in shallow-water corals. In agreement with that study, we saw a pronounced accumulation of CPs in the upper side of branches in field samples and in experimental corals grown under controlled light conditions. Apparently, not all corals demonstrate a light-regulated expression of GFP-like proteins (Leutenegger et al. 2007a). However, the high-lightinduced production of CPs supports a photoprotective function and helps to explain the depth-dependent decrease in morphs with pronounced $\mathrm{CP}$ colouration observed in a previous study (Salih et al. 2006). The co-existence of CPcontaining and $\mathrm{CP}$-free morphs in shallow water supports the assertion that protection provided by the pigments is not vital but potentially offers more subtle benefits enabling corals to acclimate to a broader range of conditions in habitats characterised by a highly dynamic light field.

Screening by CPs in regions of low symbiont density

A constrained localisation of FPs to structural features, such as skeletal ridges, is typically found where the zooxanthellae concentration is lowest (Mazel et al. 2003). It was concluded that the physical segregation from the algae would preclude FPs from playing a role in symbiont photobiology (Mazel et al. 2003). Moreover, the high-level CP expression in coral growth zones that are essentially free from zooxanthellae (D'Angelo et al. 2012) called for further analyses of the function of GFP-like proteins in these regions. Here, we investigated whether the presence of CPs could afford screening to growth regions such as coral tips or margins, regenerating colony parts or areas in which an epibiont infestation stimulated a growth-mediated immune response (D'Angelo et al. 2012). In the regenerating tissue of A. polystoma grown under low light, $\mathrm{CP}$ expression was largely absent, whereas high-light colonies amassed a 30-fold increase in CP concentration, confirming a lightdriven upregulation of $\mathrm{CP}$ expression (D'Angelo et al. 2008). CP localisation to growing areas devoid of zooxanthellae can be explained by the high internal light fluxes in the blue-green spectral range that result from the lack of absorption of incident light by the photosynthetic pigments of the symbiont and its reflection by the coral skeleton, potentially amplified by multiple scattering (Enriquez et al. 2005). The comparison of reflectance spectra of tissue areas with and without zooxanthellae suggests a 5-7-fold increase in internal fluxes of blue-green light in growing regions of the colony. A comparable increase in light intensity was proven to stimulate an enhanced production of GFP-like proteins (D'Angelo et al. 2008).

Once the symbiont population becomes established, CP expression decreases due to the reduction of internal bluelight fluxes. Consequently, the light-driven upregulation and the transient appearance of CPs in the growth zones could enable certain corals to provide screening to parts of the colony of greatest need, without compromising the 
overall productivity. Furthermore, considering that axial polyp development is blue-light dependent (Kaniewska et al. 2009), the absorption characteristics of the CPs in growth zones are ideally suited to provide screening without interfering with blue-light-regulated growth processes.

In agreement with our spectral analyses of established tissues, CP expression in regenerating tissues is clearly capable of screening the symbionts. We postulate that the presence of CPs in growth zones assists in the colonisation of new coral tissue of pigmented morphs by providing photoprotection from the high internal light fluxes associated with multiple scattering in the coral skeleton (Enriquez et al. 2005; Terán et al. 2010).

Acknowledgments The study was funded by NERC (NE/I01683X/1 \& NE/I012648/1 to JW; studentship to EGS), DFG (Wi1990/2-1 to JW), DAAD (Heron Island Fieldwork to JW), European Research Council under the European Union's Seventh Framework Programme (FP/2007-2013)/ERC Grant Agreement n. 311179 to JW and ARC (Discovery grant to AS et al.). We acknowledge the assistance of D. Owsianka (University of Southampton, LED array construction) and F. Schmitt (University of Ulm, field sampling) and thank Tropical Marine Centre (London) and Tropic Marine (Wartenberg) for sponsoring of the NOCS Coral Reef Laboratory. We would also like to thank the two anonymous reviewers and A. Banaszak for their helpful comments.

\section{References}

Alieva NO, Konzen KA, Field SF, Meleshkevitch EA, Hunt ME, Beltran-Ramirez V, Miller DJ, Wiedenmann J, Salih A, Matz MV (2008) Diversity and evolution of coral fluorescent proteins. PLoS ONE 3:e2680

Baird AH, Bhagooli R, Ralph PJ, Takahashi S (2009) Coral bleaching: the role of the host. Trends Ecol Evol 24:16-20

Brown BE, Ambarsari I, Warner ME, Fitt WK, Dunne RP, Gibb SW, Cummings DG (1999) Diurnal changes in photochemical efficiency and xanthophyll concentrations in shallow water reef corals : evidence for photoinhibition and photoprotection. Coral Reefs 18:99-105

D'Angelo C, Smith E, Oswald F, Burt J, Tchernov D, Wiedenmann J (2012) Locally accelerated growth is part of the innate immune response and repair mechanisms in reef-building corals as detected by green fluorescent protein (GFP)-like pigments. Coral Reefs 31(4):1045-1056 [doi:10.1007/s00338-012-0926-8]

D'Angelo C, Wiedenmann J (2012) An experimental mesocosm for long-term studies of reef corals. J Mar Biol Assoc UK 92:769-775

D'Angelo C, Denzel A, Vogt A, Matz MV, Oswald F, Salih A, Nienhaus GU, Wiedenmann J (2008) Blue light regulation of host pigment in reef-building corals. Mar Ecol Prog Ser 364:97-106

Dove SG, Hoegh-Guldberg O, Ranganathan S (2001) Major colour patterns of reef-building corals are due to a family of GFP-like proteins. Coral Reefs 19:197-204

Dove SG, Lovell C, Fine M, Deckenback J, Hoegh-Guldberg O, Iglesias-Prieto R, Anthony KR (2008) Host pigments: potential facilitators of photosynthesis in coral symbioses. Plant, Cell Environ 31:1523-1533
Dustan P (1982) Depth-dependent photoadaption by zooxanthellae of the reef coral Montastrea annularis. Mar Biol 68:253-264

Enriquez S, Mendez ER, Iglesias-Prieto R (2005) Multiple scattering on coral skeletons enhances light absorption by symbiotic algae. Limnol Oceanogr 50:1025-1032

Falkowski PG, Dubinsky Z (1981) Light-shade adaptation of Stylophora pistillata, a hermatypic coral from the Gulf of Eilat. Nature 289:172-174

Falkowski PG, Jokiel PL, Kinzie RA (1990) Irradiance and corals. In: Dubinsky Z (ed) Coral reefs: Ecosystems of the world. Elsevier Science, Amsterdam, pp89-107

Franklin DJ, Hoegh-Guldberg O, Jones RJ, Berges JA (2004) Cell death and degeneration in the symbiotic dinoflagellates of the coral Stylophora pistillata during bleaching. Mar Ecol Prog Ser 272:117-130

Gorbunov MY, Kolber ZS, Lesser MP, Falkowski PG (2001) Photosynthesis and photoprotection in symbiotic corals. Limnol Oceanogr 46:75-85

Hakala M, Tuominen I, Keränen M, Tyystjärvi T, Tyystjärvi E (2005) Evidence for the role of the oxygen-evolving manganese complex in photoinhibition of Photosystem II. Biochim Biophys Acta (BBA) -. Bioenergetics 1706:68-80

Hartle-Mougiou K, D'Angelo C, Smith EG, Burt J, West P, Wiedenmann J (2012) Diversity of zooxanthellae from corals and sea anemones after long-term aquarium culture. J Mar Biol Assoc UK 92:687-691

Hennige SJ, Smith DJ, Perkins R, Consalvey M, Paterson DM, Suggett DJ (2008) Photoacclimation, growth and distribution of massive coral species in clear and turbid waters. Mar Ecol Prog Ser 369:77-88

Hennige S, Suggett D, Warner M, McDougall K, Smith D (2009) Photobiology of Symbiodinium revisited: bio-physical and biooptical signatures. Coral Reefs 28:179-195

Hochberg EJ, Atkinson MJ, Apprill A, Andrefouet S (2004) Spectral reflectance of coral. Coral Reefs 23:84-95

Iglesias-Prieto R, Matta JL, Robins WA, Trench RK (1992) Photosynthetic response to elevated temperature in the symbiotic dinoflagellate Symbiodinium microadriaticum in culture. Proc Natl Acad Sci USA 89:10302-10305

Iglesias-Prieto R, Beltran VH, LaJeunesse TC, Reyes-Bonilla H, Thome PE (2004) Different algal symbionts explain the vertical distribution of dominant reef corals in the eastern Pacific. Proc R Soc B Biol Sci 271:1757-1763

Jeffrey SW, Humphrey GF (1975) New spectrophotometric equations for determining chlorophylls a, b, c1 and $\mathrm{c} 2$ in higher plants, algae and natural phytoplankton. Biochemie und Physiologie der Pflanzen 167:191-194

Kaniewska P, Campbell PR, Fine M, Hoegh-Guldberg O (2009) Phototropic growth in a reef flat acroporid branching coral species. J Exp Biol 212:662-667

Kaniewska P, Magnusson SH, Anthony KRN, Reef R, Kühl M, Hoegh-Guldberg O (2011) Importance of macro- versus microstructure in modulating light levels inside coral colonies. J Phycol $47: 846-860$

Kirk JTO (1994) Light and photosynthesis in aquatic ecosystems. Cambridge University Press, Cambridge

Kuhl M, Cohen Y, Dalsgaard T, Jorgensen BB, Revsbech NP (1995) Microenvironment and photosynthesis of zooxanthellae in scleractinian corals studied with microsensors for $\mathrm{O}_{2}, \mathrm{pH}$ and light. Mar Ecol Prog Ser 117:159-172

LaJeunesse T (2002) Diversity and community structure of symbiotic dinoflagellates from Caribbean coral reefs. Mar Biol 141:387-400

Lesser MP (2006) Oxidative stress in marine environments: biochemistry and physiological ecology. Annu Rev Physiol $68: 253-278$ 
Lesser MP, Mazel C, Phinney D, Yentsch CS (2000) Light absorption and utilization by colonies of the congeneric hermatypic corals Montastraea faveolata and Montastraea cavernosa. Limnol Oceanogr 45:76-86

Lesser MP, Slattery M, Stat M, Ojimi M, Gates RD, Grottoli A (2010) Photoacclimatization by the coral Montastraea cavernosa in the mesophotic zone: light, food, and genetics. Ecology 91:990-1003

Leutenegger A, Kredel S, Gundel S, D'Angelo C, Salih A, Wiedenmann J (2007a) Analysis of fluorescent and non-fluorescent sea anemones from the Mediterranean Sea during a bleaching event. J Exp Mar Biol Ecol 353:221-234

Leutenegger A, D'Angelo C, Matz MV, Denzel A, Oswald F, Salih A, Nienhaus GU, Wiedenmann J (2007b) It's cheap to be colorful. Anthozoans show a slow turnover of GFP-like proteins. FEBS J 274:2496-2505

Levy O (2003) Photobehavior of stony corals: responses to light spectra and intensity. J Exp Biol 206:4041-4049

Levy O, Dubinsky Z, Schneider K, Achituv Y, Zakai D, Gorbunov MY (2004) Diurnal hysteresis in coral photosynthesis. Mar Ecol Prog Ser 268:105-117

Levy O, Achituv Y, Yacobi YZ, Stambler N, Dubinsky Z (2006) The impact of spectral composition and light periodicity on the activity of two antioxidant enzymes (SOD and CAT) in the coral Favia favus. J Exp Mar Biol Ecol 328:35-46

Liakopoulos G, Nikopoulos D, Klouvatou A, Vekkos K-A, Manetas Y, Karabourniotis G (2006) The photoprotective role of epidermal anthocyanins and surface pubescence in young leaves of grapevine (Vitis vinifera). Ann Bot 98:257-265

Marsh JA Jr (1970) Primary productivity of reef-building calcareous red algae. Ecology 51:255-263

Matz MV, Fradkov AF, Labas YA, Savitsky AP, Zaraisky AG, Markelov ML, Lukyanov SA (1999) Fluorescent proteins from nonbioluminescent Anthozoa species. Nat Biotechnol 17:969-973

Mazel CH, Lesser MP, Gorbunov MY, Barry TM, Farrell JH, Wyman KD, Falkowski PG (2003) Green-fluorescent proteins in Caribbean corals. Limnol Oceanogr 48:402-411

McCabe Reynolds J, Bruns BU, Fitt WK, Schmidt GW (2008) Enhanced photoprotection pathways in symbiotic dinoflagellates of shallow-water corals and other cnidarians. Proc Natl Acad Sci USA 105:13674-13678

Merzlyak MN, Melø TB, Naqvi KR (2008) Effect of anthocyanins, carotenoids, and flavonols on chlorophyll fluorescence excitation spectra in apple fruit: signature analysis, assessment, modelling, and relevance to photoprotection. J Exp Bot 59:349-359

Nienhaus GU, Wiedenmann J (2009) Structure, dynamics and optical properties of fluorescent proteins: perspectives for marker development. ChemPhysChem 10:1369-1379

Parsons TR, Strickland JDH (1963) Discussion of spectrophotometric determination of marine-plant pigments, with revised equations for ascertaining chlorophylls and carotenoids. J Mar Res $21: 155-163$

Salih A, Hoegh-Guldberg O, Cox G (1998) Photoprotection of symbiotic dinoflagellates by fluorescent pigments in reef corals. Proceedings of the Australian Coral Reef Society 75th Anniversary Conference School of Marine Science, The University of Queensland, Brisbane, pp217-230

Salih A, Larkum A, Cox G, Kuhl M, Hoegh-Guldberg O (2000) Fluorescent pigments in corals are photoprotective. Nature 408:850-853

Salih A, Cox G, Szymczak R, Coles S, Baird A, Dunstan A, Cocco G, Mills J, Larkum A (2006) The role of host-based color and fluorescent pigments in photoprotection and in reducing bleaching stress in corals. Proc 10th Int Coral Reef Symp:746-756

Smith DJ, Suggett DJ, Baker NR (2005) Is photoinhibition of zooxanthellae photosynthesis the primary cause of thermal bleaching in corals? Global Change Biol 11:1-11
Stambler N, Dubinsky Z (2005) Corals as light collectors: an integrating sphere approach. Coral Reefs 24:1-9

Takahashi S, Whitney SM, Badger MR (2009) Different thermal sensitivity of the repair of photodamaged photosynthetic machinery in cultured Symbiodinium species. Proc Natl Acad Sci USA 106:3237-3242

Takahashi S, Milward SE, Yamori W, Evans JR, Hillier W, Badger MR (2010) The solar action spectrum of Photosystem II damage. Plant Physiol 153:988-993

Tchernov D, Gorbunov MY, de Vargas C, Narayan Yadav S, Milligan AJ, Haggblom M, Falkowski PG (2004) Membrane lipids of symbiotic algae are diagnostic of sensitivity to thermal bleaching in corals. Proc Natl Acad Sci USA 101:13531-13535

Terán E, Méndez ER, Enríquez S, Iglesias-Prieto R (2010) Multiple light scattering and absorption in reef-building corals. Appl Opt 49:5032-5042

Veal CJ, Carmi M, Dishon G, Sharon Y, Michael K, Tchernov D, Hoegh-Guldberg O, Fine M (2010) Shallow-water wave lensing in coral reefs: a physical and biological case study. J Exp Biol 213:4304-4312

Visram S, Wiedenmann J, Douglas AE (2006) Molecular diversity of symbiotic algae of the genus Symbiodinium (Zooxanthellae) in cnidarians of the Mediterranean Sea. J Mar Biol Assoc UK 86:1281-1283

Vogt A, D'Angelo C, Oswald F, Denzel A, Mazel CH, Matz MV, Ivanchenko S, Nienhaus GU, Wiedenmann J (2008) A green fluorescent protein with photoswitchable emission from the deep sea. PLoS ONE 3:e3766

Warner ME, Fitt WK, Schmidt GW (1996) The effects of elevated temperature on the photosynthetic efficiency of zooxanthellae in hospite from four different species of reef coral: a novel approach. Plant, Cell Environ 19:291-299

Warner ME, Fitt WK, Schmidt GW (1999) Damage to photosystem II in symbiotic dinoflagellates: a determinant of coral bleaching. Proc Natl Acad Sci USA 96:8007-8012

Warner ME, Lesser MP, Ralph PJ (2010) Chlorophyll fluorescence in reef building corals. In: Suggett DJ, Prášil O, Borowitzka MA (eds) Chlorophyll a fluorescence in aquatic sciences: methods and applications. Springer, Netherlands, pp209-222

Wiedenmann J, Rocker C, Funke W (1999) The morphs of Anemonia aff. sulcata (Cnidaria, Anthozoa) in particular consideration of the ectodermal pigments. In: Pfadenhauer J (ed) Verhandlungen der Gesellschaft für Ökologie. Spektrum Akademischer Verlag, Heidelberg, pp 497-503

Wiedenmann J, Elke C, Spindler KD, Funke W (2000) Cracks in the beta-can: fluorescent proteins from Anemonia sulcata (Anthozoa, Actinaria). Proc Natl Acad Sci USA 97:14091-14096

Wiedenmann J, Schenk A, Rocker C, Girod A, Spindler KD, Nienhaus GU (2002) A far-red fluorescent protein with fast maturation and reduced oligomerization tendency from Entacmaea quadricolor (Anthozoa, Actinaria). Proc Natl Acad Sci USA 99:11646-11651

Wiedenmann J, Ivanchenko S, Oswald F, Nienhaus GU (2004a) Identification of GFP-like proteins in nonbioluminescent, azooxanthellate anthozoa opens new perspectives for bioprospecting. Mar Biotechnol (NY) 6:270-277

Wiedenmann J, Ivanchenko S, Oswald F, Schmitt F, Rocker C, Salih A, Spindler KD, Nienhaus GU (2004b) EosFP, a fluorescent marker protein with UV-inducible green-to-red fluorescence conversion. Proc Natl Acad Sci USA 101:15905-15910

Wiedenmann J, D'Angelo C, Smith EG, Hunt AN, Legiret FE, Postle AD, Achterberg, EP (2012) Nutrient enrichment can increase the susceptibility of reef corals to bleaching. Nature Climate Change [doi:10.1038/nclimate1661] 


\title{
Screening by coral green fluorescent protein (GFP)-like chromoproteins supports a role in photoprotection of zooxanthellae
}

\author{
E. G. Smith • C. D'Angelo • A. Salih •
}

J. Wiedenmann

\section{Electronic Supplementary Materials}

\section{ESM Methods}

\section{Fluorescence spectroscopy}

The excitation spectrum of PSII emission at $680 \mathrm{~nm}$ was measured from 400-620nm with excitation and emission slits widths of $10 \mathrm{~nm}$ and $5 \mathrm{~nm}$, respectively. We conducted initial fluorescence excitation and emission measurements on all studied species to ensure that emission at $680 \mathrm{~nm}$ was solely due to chlorophyll emission (ESM Fig. S7) with no interference from other fluorophores such as red fluorescent proteins. For comparison of coral tissues with different pigmentation, the chlorophyll excitation spectra were normalised to the $460 \mathrm{~nm}$ peak under the assumption that excitation at $460 \mathrm{~nm}$ is unaffected by host pigments (Mazel et al. 2003).

Excitation difference spectra were calculated to explore the spectral nature of the pigments driving the observed changes in chlorophyll excitation spectra. Here, the chlorophyll excitation of $\mathrm{CP}$ pigmented tissue was subtracted from the non-CP pigmented tissue and the difference was normalised to the excitation at that wavelength of the brown morph. As an example, an excitation difference value of 0.5 would represent $50 \%$ lower excitation of chlorophyll in the $\mathrm{CP}$ pigmented tissue compared to the non- $\mathrm{CP}$ pigmented tissue at that specific wavelength. The excitation difference spectra peaks were consistent across the chlorophyll emission spectrum (ESM Fig. S7c).

\section{CP quantification}

In order to enable quantification of avalCP580 and apolCP582, the molar extinction coefficients of these CPs were determined using the alkaline denaturation method (Kredel et al. 2008). As the amino acid sequence for these CPs was unknown, the molecular weight of CPs was estimated by averaging the molecular weights of five acroporiid CPs (GenBank: AAU06853.1, AAU06856.1, AAU06855.1, AAU06854.1, ACH089425.1) (Alieva et al. 2008; D'Angelo et al. 2008) calculated with Lasergene's Protean software (DNASTAR, USA). Considering the low standard deviation $( \pm 0.23 \%)$ of the individual molecular weights from the mean $(25 \mathrm{kDa})$, the estimates can be expected to be representative.

The CP concentration in clarified protein extracts from the purple morph of $A$. valida, and from the growth zones of $A$. polystoma under two light conditions was quantified by spectral unmixing using the method of least squares (Settle and Drake 1993; Hedley et al. 2004). This study uses absorption spectra in the unmixing as, according to Beer's Law, the absorption of a mixture can be considered to be the additive sum of the weighted absorption coefficients of the components within the mixture (Kirk 1994). The endmember spectra used in the twoendmember unmixings were the purified CP spectrum and the spectrum of a clarified protein extract taken from an independent tissue sample from the respective species (A. valida - brown morph; A. polystoma - low light). All spectral unmixings were performed on clarified tissue extracts with absorption readings less than 1.0 to ensure linearity. CP concentrations were calculated using the extinction coefficients and were normalised to the total soluble protein concentrations (BCA assay, Pierce) and/or the coral surface.

\section{References}

Alieva NO, Konzen KA, Field SF, Meleshkevitch EA, Hunt ME, Beltran-Ramirez V, Miller DJ, Wiedenmann J, Salih A, Matz MV (2008) Diversity and evolution of coral fluorescent proteins. PLoS ONE 3:e2680

D'Angelo C, Denzel A, Vogt A, Matz MV, Oswald F, Salih A, Nienhaus GU, Wiedenmann J (2008) Blue light regulation of host pigment in reefbuilding corals. Mar Ecol Prog Ser 364:97-106

Hedley JD, Mumby PJ, Joyce KE, Phinn SR (2004) Spectral unmixing of coral reef benthos under ideal conditions. Coral Reefs 23:60-73 
Kirk JTO (1994) Light and photosynthesis in aquatic ecosystems. Cambridge University Press, Cambridge

Kredel S, Nienhaus K, Oswald F, Wolff M, Ivanchenko S, Cymer F, Jeromin A, Michel FJ, Spindler K-D, Heilker R, Nienhaus GU, Wiedenmann J (2008) Optimized and far-redemitting variants of fluorescent protein eqFP611.
Chem Biol (Lond) 15:224-233

Mazel CH, Lesser MP, Gorbunov MY, Barry TM, Farrell JH, Wyman KD, Falkowski PG (2003) Green-fluorescent proteins in Caribbean corals. Limnol Oceanogr 48:402-411

Settle JJ, Drake NA (1993) Linear mixing and the estimation of ground cover proportions. Int $\mathbf{J}$ Remote Sens 14:1159-1177
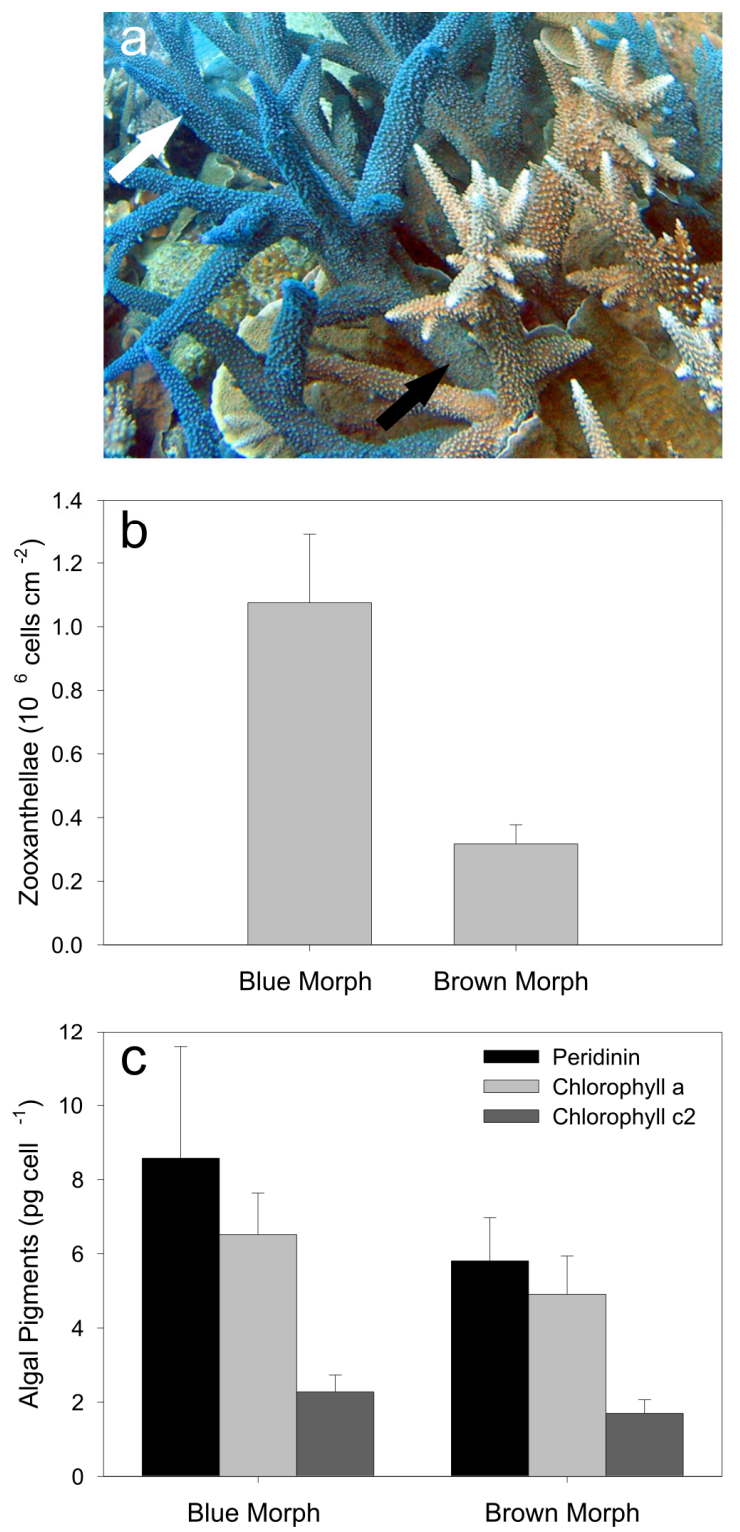

ESM Figure S1. Analysis of blue and brown morphs of Acropora nobilis from the Great Barrier Reef. (a) Photograph of the two morphs side-by-side on the reef. The white arrow indicates a light exposed branch whereas the dark arrow shows a branch that is subject to self shading within the blue morph colony. (b, c) Mean zooxanthellae densities (b) and pigment concentrations (c) from five replicate colonies collected at $\mathbf{1 . 5} \mathrm{m}$. Error bars indicate the \pm SD of the mean. 


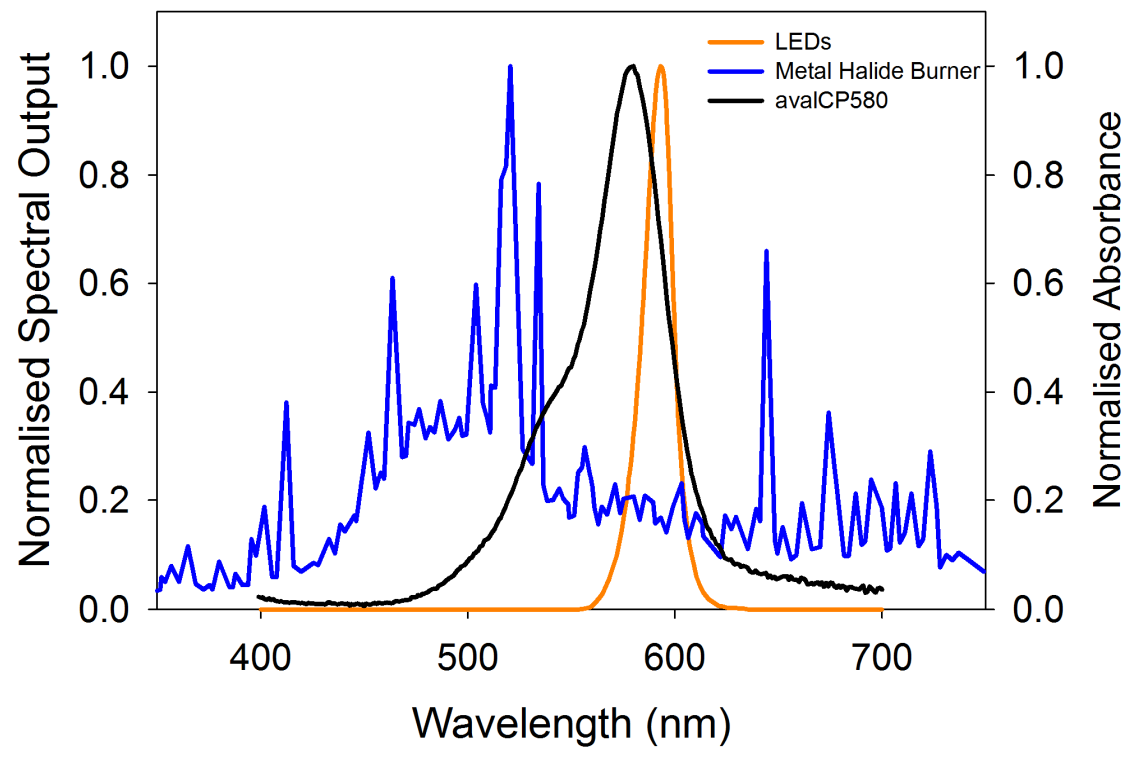

ESM Figure S2. Optical properties of the light sources used in this study. The normalised spectral output of the metal halide burners used for growing the aquarium corals and the amber LEDs used for the high irradiance experiments. The absorption spectrum for avalCP580 is shown to demonstrate the overlap between the LED output and the absorption of the $\mathrm{CP}$.

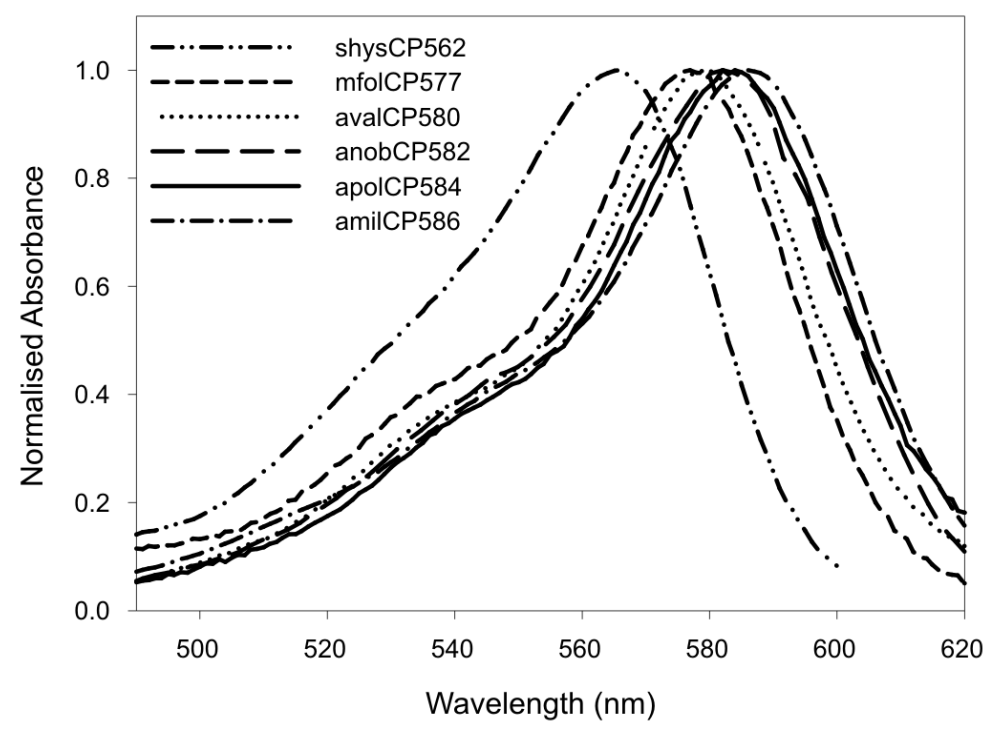

ESM Figure S3. Absorption spectra of CPs isolated and purified from the corals Seriatopora hystrix (shysCP562), Montipora foliosa (mfolCP577), Acropora valida (avalCP580), Acropora nobilis (anobCP582), Acropora polystoma (apolCP584) and Acropora millepora (amilCP586). Spectra are normalised to a peak height of 1.0. 


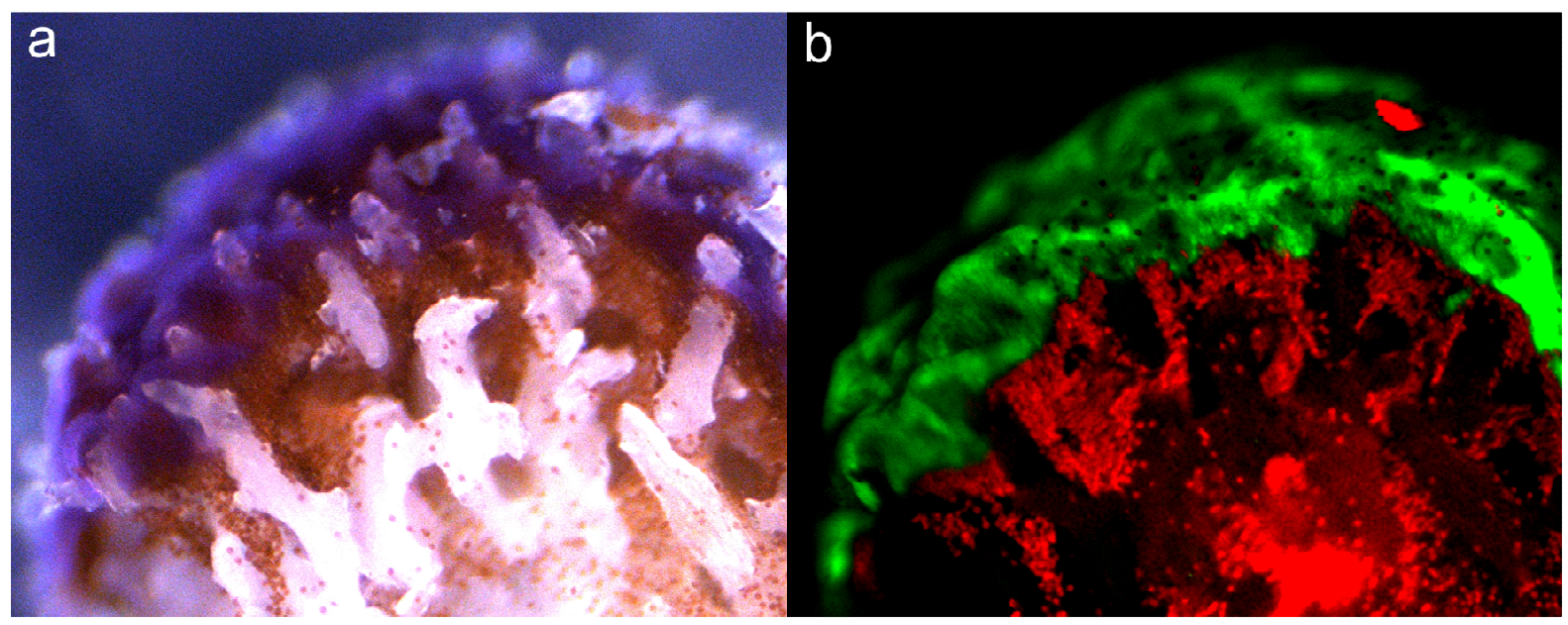

ESM Figure S4. Localisation of avalCP580 in the purple morph of Acropora valida. (a) Micrograph of a cross section of an $A$. valida tip showing the localisation of the purple chromoprotein. (b) Fluorescent image of the corresponding cross section showing the presence of ectodermal green fluorescent proteins (green) and chlorophyll fluorescence from the zooxanthellae (red).
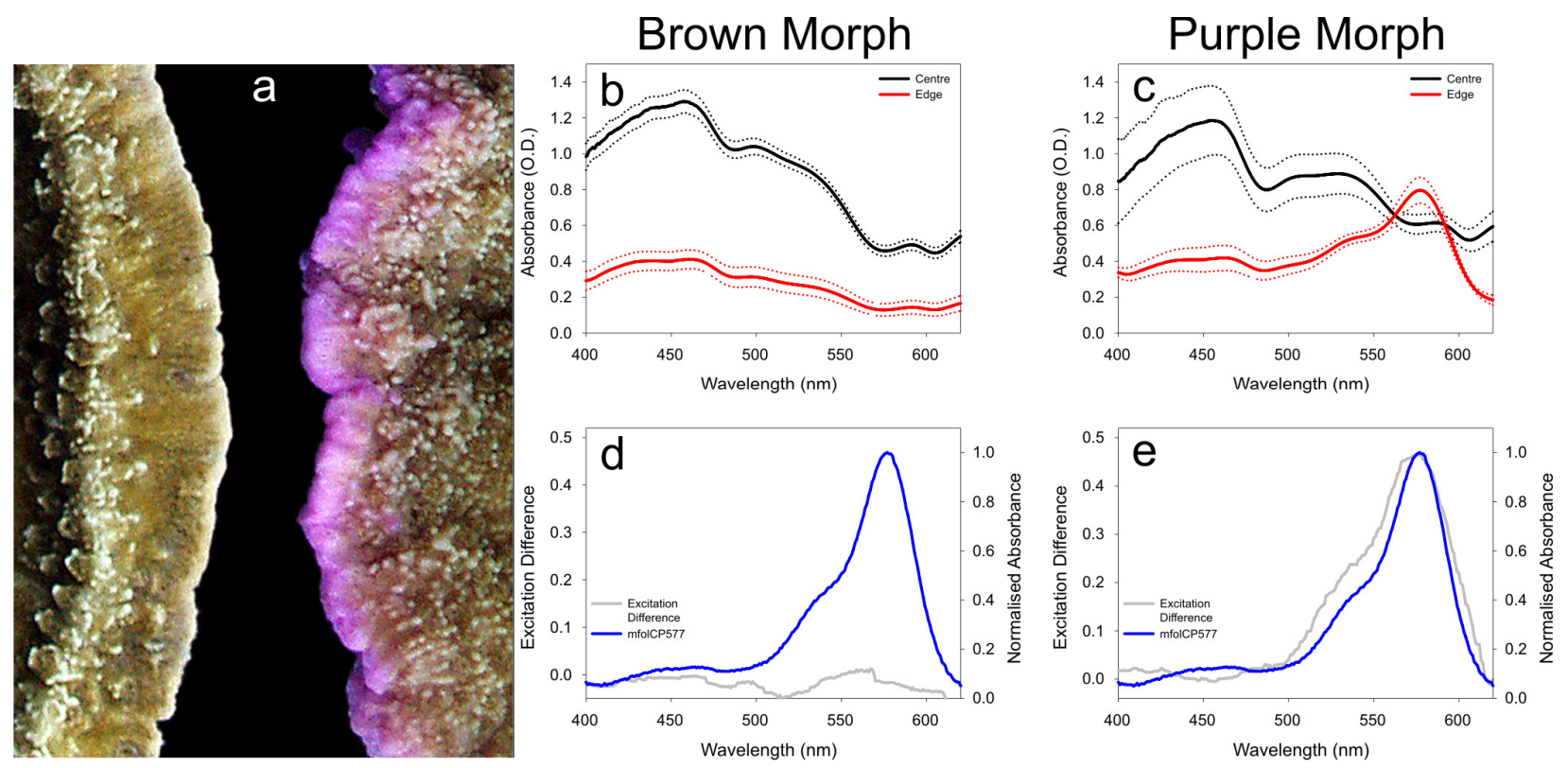

ESM Figure S5. Characterisation of chromoproteins in growth regions. (a) Photograph of two Montipora foliosa morphs expressing (right) and not expressing (left) chromoproteins in the colony margins. (b, c) Mean approximated absorbance spectra of the brown (b) and purple morphs (c) at the centre and growth margins of the colonies. Dotted lines indicate the \pm SD of 5 independent measurements. (d, e) Excitation difference spectra for the brown (d) and purple (e) morphs. The absorption spectra of mfolCP577 are shown for reference. 


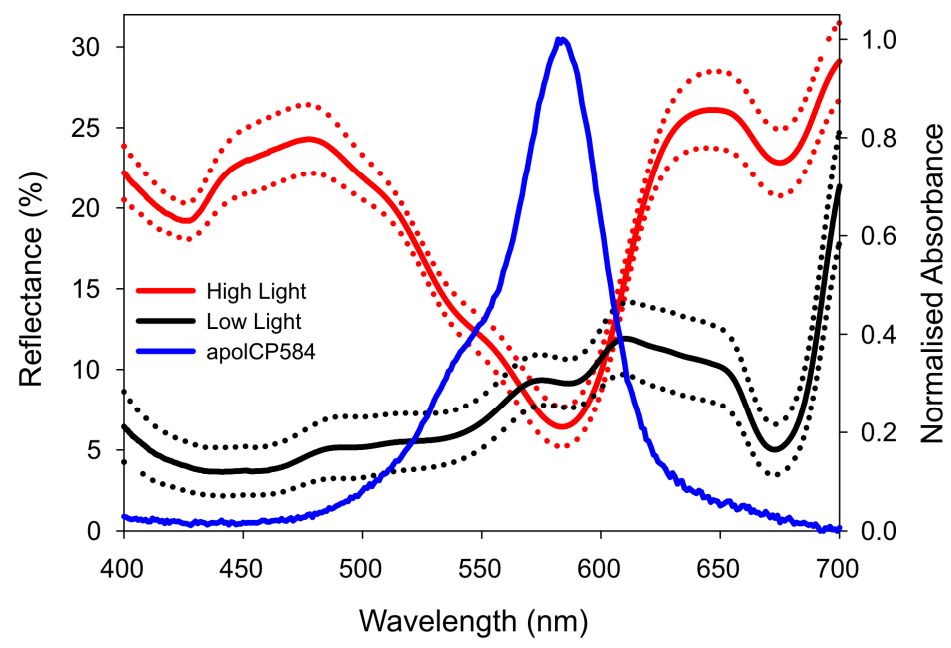

ESM Figure S6. Reflectance spectra of regenerating zones in Acropora polystoma. The solid lines show the mean reflectance of the high and low light regeneration zones with the standard deviations of 5 measurements shown by the dotted lines. The absorption spectrum of apolCP584 is shown for comparison.
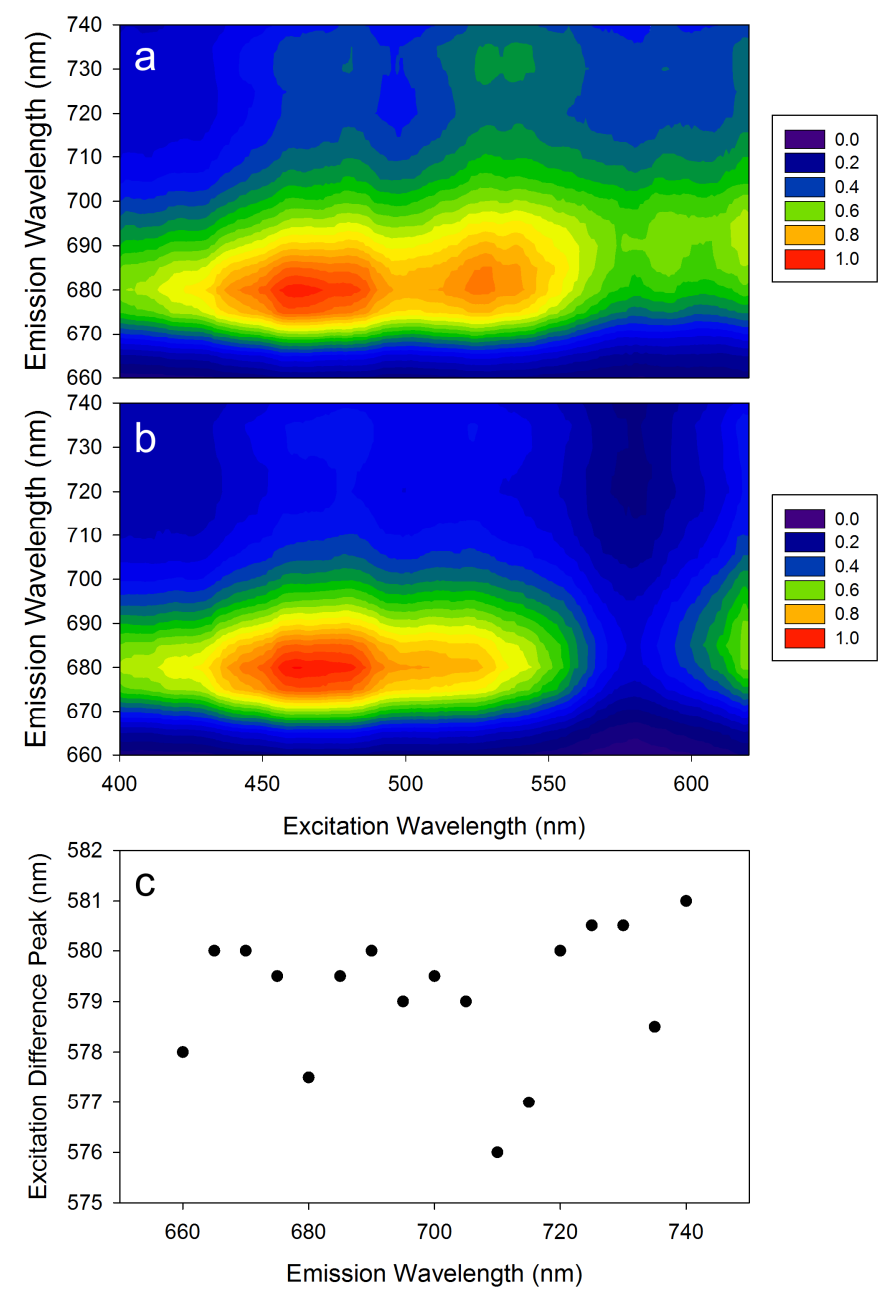

ESM Figure S7. Excitation and emission properties of the brown and purple colour morphs of Acropora valida. (a, b) Excitation-emission plot for the brown (a) and purple (b) morphs. The excitation spectra are sampled at $1 \mathrm{~nm}$ intervals and the emission spectra are sampled every 5 $\mathrm{nm}$. (c) Difference spectrum peak values across the chlorophyll emission range. The mean peak wavelength of the difference spectrum is $579 \mathrm{~nm}$ with a standard deviation of $1 \mathrm{~nm}$ and the respective $\mathrm{CP}$ absorption peak is at $580 \mathrm{~nm}$. 